\title{
A novel technique for pediatric femoral locked submuscular plate removal: the 'push-pull' technique
}

\author{
Martin F Hoffmann ${ }^{1 *}$, John Gburek ${ }^{2}$ and Clifford B Jones ${ }^{3}$
}

\begin{abstract}
Submuscular and minimally invasive plate insertion is gaining popularity reducing the need for large open approaches and resulting in a smaller operative 'footprint.' With pediatric fractures and titanium implants, fibrous and osseous ingrowth to the implant and osseous implant integration may interfere with implant removal. Therefore, the small minimally invasive implant insertion procedure may require a large maximally invasive exposure for implant removal after fracture healing. To reduce soft tissue damage, bleeding, scarring, and pain associated with implant removal, a minimally invasive procedure utilizing the pre-existing incisions while controlling the implant is efficient and beneficial. The surgical technique is described, and a case series of 21 treated pediatric femoral fractures illustrates the successful performance of the procedure and its limitations.
\end{abstract}

\section{Background}

Locked plating is very popular with increasing locked plating indications [1]. The main indications of locked plating are poor bone quality, fracture comminution and/or bone loss, and short segment fixation [2,3]. Additionally, submuscular and minimally invasive plate insertion is gaining popularity reducing the need for large open approaches, interfragmentary fixation, and bone grafting [4-8], and resulting in smaller, more cosmetically appearing scars [9]. Bridge plating with or without locked screws utilizes balanced fixation relying on longer plates and selective screw insertion leaving many screw hole sites empty. With plate irritation, patient preference, or surgeon preference, removal of submuscular plates may become necessary [10-15].

A controversy exists regarding routine implant removal in children [16]. Routine removal in children was justified based on potential future risks, and many institutions offer routine removal of implants to skeletally immature patients [17-19]. Resulting thereof, $60 \%$ to $90 \%$ of all implant removals in children are performed electively [17,20,21]. Implant removal is not without complications or consequences [14,22-25]. The problem with submuscular

\footnotetext{
* Correspondence: martinfhoffmann@gmx.net

'Grand Rapids Medical Education Partners, 1000 Monroe Ave NW, Grand Rapids, MI 49503, USA

Full list of author information is available at the end of the article
}

insertion especially with titanium implants and pediatric patients is that fibrous and osseous ingrowth to the implant interferes with implant removal [26] (Figure 1). This may lead surgeons to use more extensive approaches for implant removal. Noticeably wider and cosmetically disadvantageous scars after implant removal compared to the initial approach have been reported (Figure 2). In one study, 3.6\% of the patients had asked to see a plastic surgeon [27]. Some innovative techniques have been described to remove pelvic and spinal implants via minimally invasive techniques $[28,29]$. To our knowledge, no technique for minimally invasive implant removal on long bones has been described. Routine hardware removal is offered most often to pediatric patients [17]. Therefore, we have chosen purposefully a pediatric study population.

\section{Methods \\ Technique}

Final radiographs are preoperatively evaluated and confirmed for fracture healing, manufacturer type, and screw (standard versus locked) position. Appropriate screwdrivers are confirmed. The lower extremity is placed on a radiolucent table. The fluoroscopic imaging unit is brought in from the contralateral side of the table from the implant. Therefore, laterally applied femoral or tibial implants have the fluoroscope imaging coming 


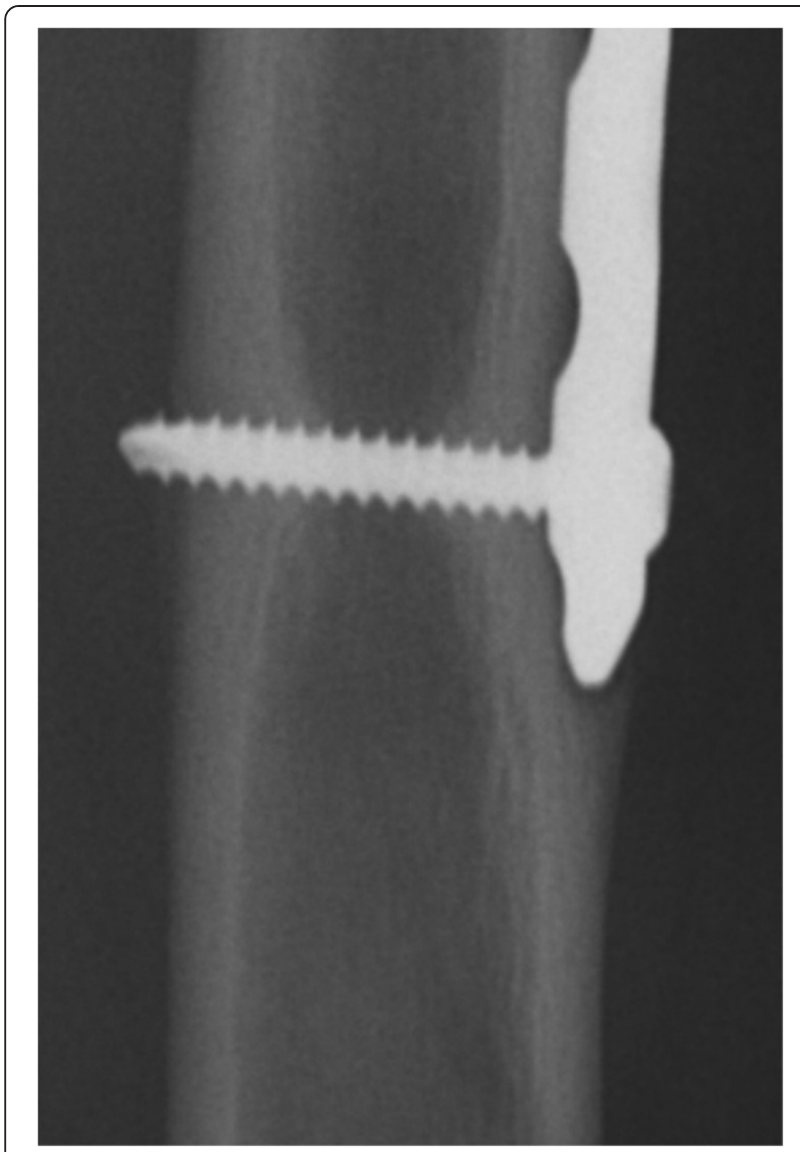

Figure 1 Bone beginning to grow over distal end of plate after osteosynthesis for pediatric femoral fracture.

from the contralateral side while medially applied tibial plates have the fluoroscopic unit on the ipsilateral side. Screw positions with the incisions and the fluoroscopic unit were confirmed. With reduced fractures and swelling after healing, the incisions may not line up perfectly with the screw sites. Small incisions corresponding to the screw sites were made. The limb was rotated so that

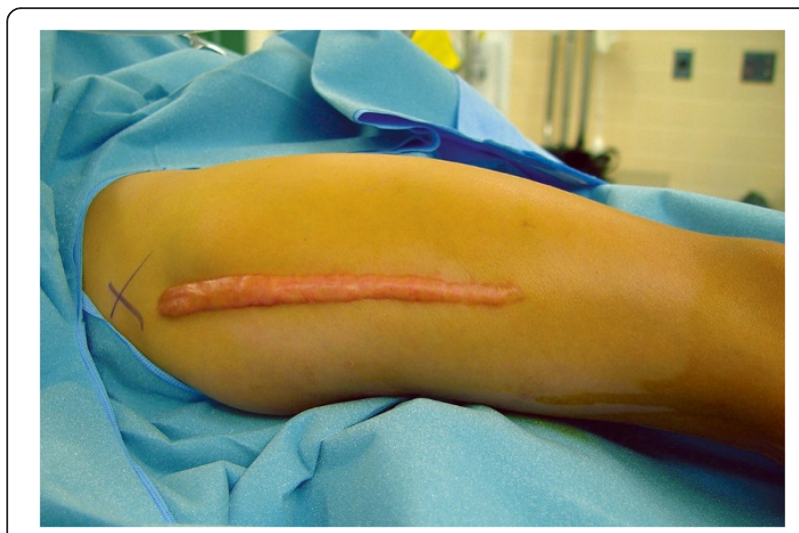

Figure $\mathbf{2}$ Cosmetically disadvantageous keloid formation after open approach to the femur. the screw heads and implant are perpendicular to the imaging unit to improve visualization and triangulation of the screwdriver head. Once the screwdriver head is adjacent to the screw head, the anterior and posterior aspect of the plate was palpated with the screwdriver head to insure positioning in the sagittal plane. When the screwdriver is positioned appropriately in all planes (axial, coronal, and sagittal), the screwdriver head was tapped gently with a mallet while carefully reversing the screwdriver head (similar to a jeweler). Once initially seeded into the screw head, the screwdriver was further tapped until placed deep into the concavity of the screw head. Utilizing the fluoroscopic magnification will improve visualization and confirm positioning. The screw was reversed from the plate while applying pressure on the screwdriver head to avoid losing contact. Once the screw tip is within the near cortex, the screw head was grasped with a hemostat or needle driver. The screw was fully removed with a coordinated effort of gentle pressure from the screwdriver and axial removal from the hemostat or needle driver.

Once all the screws are removed, the incision that was initially created was opened to insert the plate. The soft tissue attachments from the end of the plate were cleared off. The plate was gently elevated off the bone with a Cobb elevator. The shoulder hook (Zimmer Inc., Warsaw, IN, USA) (Figure 3 (a)) was slipped under the plate and through a screw hole. Through a screw hole site and incision along the other end of the plate, the curved bone tamp (Synthes, Paoli, PA, USA) was percutaneously inserted (Figure 3 (b)). With a coordinated effort, the implant was gently pulled with the shoulder hook and pushed with the bone tamp (Figure 4). Hitting the angled tamp with a mallet is usually required for release of the fibrous and osseous ingrowths. The plate will usually have an initial release, which is related to the plastic deformation of the fibrous tissue. Once the plate escapes the release from the tissues, it will move quickly and with ease. To avoid the plate from

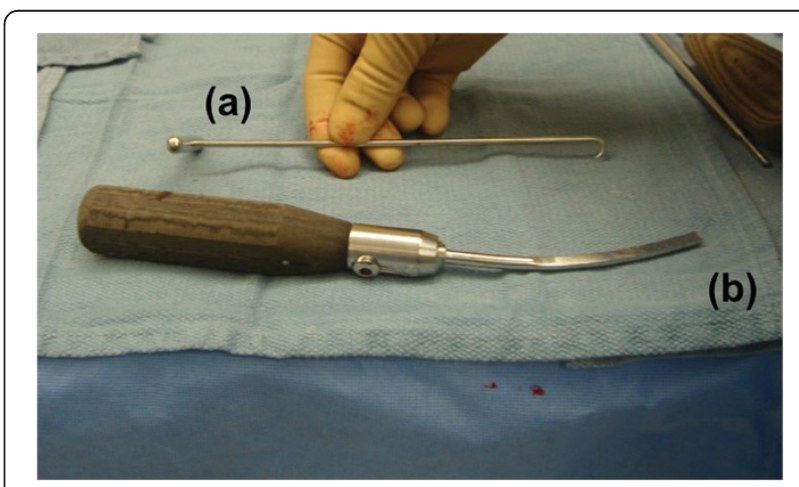

Figure 3 Shoulder hook (a) and bone tamp (b) for percutaneous implant removal. 


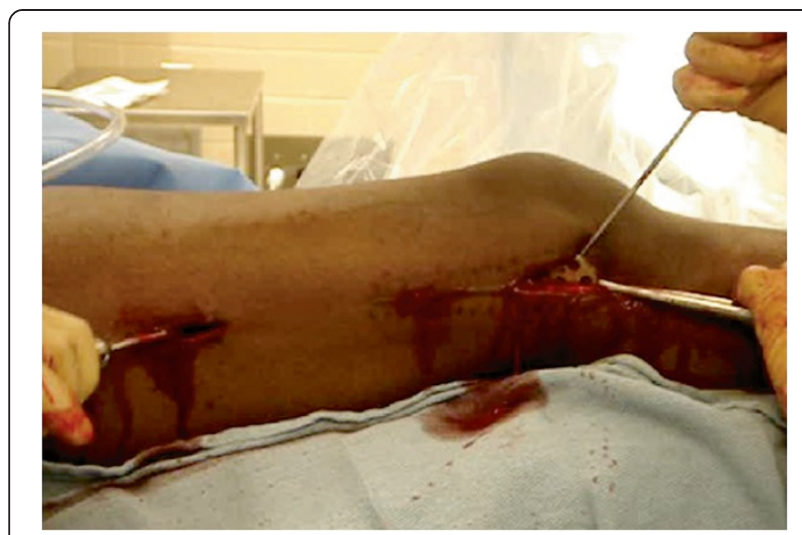

Figure 4 Pushing and pulling in a combined effort removes the implant with minimal soft tissue damage.

scratching the skin upon removal, the shoulder hook was kept angled slightly upward. If a deep incision is present from obesity or muscularity, the Cobb elevator was kept under the plate to protect the skin and direct the plate removal. To avoid the plate to quickly escape the control of the shoulder hook upon removal, the shoulder hook was gently but not aggressively pulled on.

Once the plate is removed and bleeding assessed, the larger incision fascia was closed with absorbable sutures. The skin was closed with nylon or Vicryl sutures (Figure 5). The incisions were infiltrated with $0.25 \%$ Marcaine based upon body weight limitations. A minimally compressive dressing was applied. Although possibly controversial, the patient was allowed weight bearing as tolerated [30-32]. Once able, the patient was allowed to return to normal activities.

\section{Case series}

A retrospective evaluation of plate removal after submuscular plate insertion in pediatric patients was performed in one level I trauma center. All patients were initially treated, and implant removal was performed by the senior author (CBJ). Submuscular insertion techniques and

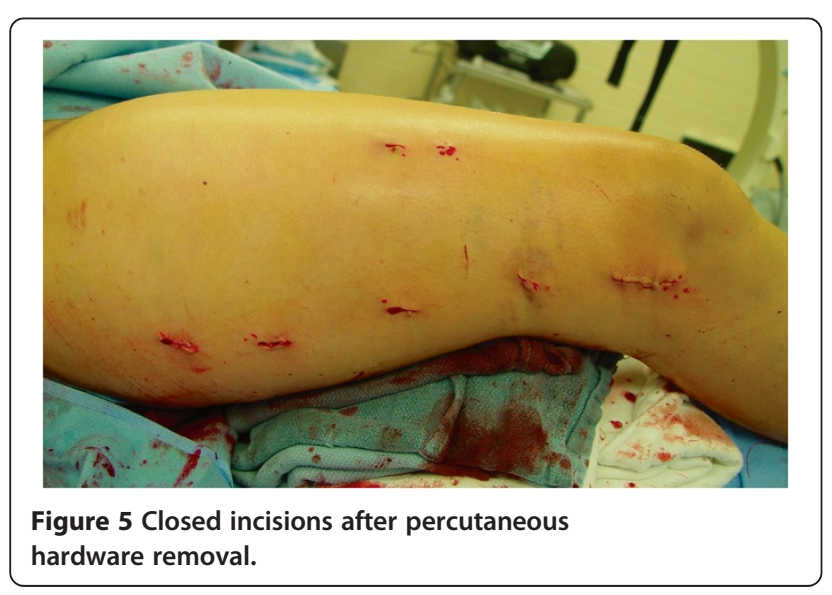

patients were identified from a registry using CPT codes 27506, 27507, 27511, 27513, and 27514 of plated pediatric femoral fractures between 2005 and 2010. Patients were followed up in a single private practice.

We recorded the age at injury, the length of the plate used, and the numbers of screws placed. We recorded the time from plate insertion to plate removal. Charts were reviewed to determine the stated reason for removal. Radiographs were reviewed to determine any bony overgrowth. Operative records and office notes were reviewed to determine any noted complications during removal and postoperatively. Ethical standards were followed in the conduct and dissemination of the study.

\section{Results}

We identified 26 patients at our institution that underwent submuscular plating for femoral fractures during the study period. Thereof, 21 (81\%) implants were removed using the described submuscular technique in all cases. Four patients were followed up in their home towns, and one patient with paraplegia did not undergo hardware removal.

The average age at the time of surgery was 8 years (range, 3 to 12 years). The documented reason for plate removal was the surgeon's recommendation [18], beginning bone overgrowth [1], and pain or irritation [2]. The median plate length was 14 holes (range, 8 to 18 holes). The mean number of proximal as well as distal screws was 2 (2 to 3 ). Plates were twenty $3.5-\mathrm{mm}$ locking compression plates (Synthes) and one $3.5-\mathrm{mm}$ compression plate (Zimmer Inc.). The mean time from plate insertion to plate removal was 8.0 months (range, 4.0 to 26.6 months).

Because of implant removal difficulties, one patient (4.8\%) required a change of the procedure to an open approach. The complication was caused by a cold welded screw head. Another patient had an anticipated broken screw, which could be retrieved completely through one of the incisions. All implants were removed completely. No postoperative complications regarding hematoma formation, wound healing problems, infections, or nerve injuries were recorded.

\section{Discussion}

Submuscular plating of pediatric femoral fractures has become a useful treatment option [33,34]. Multiple reasons, fears, and complaints of both patients and orthopedic surgeons result in the removal of previously implanted fixation devices. To avoid complete osseous integration of the implant, surgeons recommend removal of all pediatric implants used for fixation of long bone fractures [16]. Concern has been voiced regarding a more invasive and open approach for implant removal than for fracture fixation affecting pain, bleeding, healing, cosmesis, and patient satisfaction [27]. 
In our attempt to avoid extensive approaches for implant removal procedures after initially submuscularly inserted plates, we found this novel 'push-pull' technique an extremely useful tool. Open approaches with a 'second hit' on soft tissues and additional scarring were avoided in $92 \%$ of our patient population. Additionally, no complications regarding hematoma formation, wound healing problems, infections, or nerve injuries were noted. In performing the procedure correctly, careful tapping of the bone tamp with a mallet and coordinated pulling of the shoulder hook to guide plate removal avoid forceful removal with a clamp or hook. Therefore, we consider the procedure as safe and effective when performed for the right indication.

Indications for submuscular plate removal are wellhealed fractures without complete osseous overgrowth of the implant void of overlying neurovascular structures. Therefore, lateral femoral, lateral proximal tibial, and medial tibial areas are well suited for this technique. The distal lateral tibial pilon could be removed with this technique but with caution to avoid injury to the overlying anterior tibial artery and nerve upon removal. The humerus and forearm have many crossing neurovascular structures; therefore, percutaneous plate removal should be discouraged. Even though not personally experienced, percutaneous plate removal in settings of osseous overgrowth should not be attempted [9]. Even with open techniques, plate removal can be problematic with laborious removal of all osseous ingrowth and overgrowth. Screw-related complications are uncommon and not predictable. With previously diagnosed broken screws, stripped screw heads, or cross-threaded locked screw heads, wider incisions or open techniques of successful plate removal should be encouraged. If the screwdriver will not seat in the screw head, an incision will be made to expose the screw head, the debris will be removed within the screw head, and the osseous material around the screw head and within the screw hole will be removed to avoid screw head stripping, which necessitates a larger approach and possibly inability to remove the plate without more invasive and aggressive methods. If the screw head is cross-threaded and cold worked into the threaded screw hole, the head may need to be drilled out, the plate cut with a diamondtipped wheel leaving metal debris in the soft tissues, or the plate pulled off the osteopenic bone [26]. With friable skin or skin conditions, expanding the incisional length will avoid ripping the skin edges upon plate removal or bone tamp manipulation.

Although not as efficient, the surgeon can successfully remove the plate with alternative devices. Although not small and as easily inserted, a bone hook can be substituted for a shoulder hook. Since the shoulder hook has a ' $\mathrm{T}$ '-shaped end, any substitution should allow for rotational control of the device. Also, a traditional bone tamp may be utilized but must be able to fit within the screw hole shape and have an incision large enough for angled insertion. To diminish the risk of bleeding or creating injury to the bone or soft tissue, sharp instruments for pushing such as a periosteal elevator or osteotome were avoided. The smaller sharp instrument may inadvertently slip through the screw hole creating a fracture in the bone or past point distally outside the screw hole injuring the muscle or possibly a vessel.

We acknowledge the limitations of our study. The major limitation of this study was its retrospective design and the small number of patients. Additionally, patient satisfaction was not addressed utilizing standardized questionnaires. The surgical outcome or complications were not compared to a contemporaneous control group.

This study is a structured description of a technical trick in combination with a single-center case series. Therefore, this study has the potential to reflect technical difficulties and complication incidence.

\section{Conclusion}

Minimally invasive removal of long bone plating in pediatric patients can be successfully performed utilizing the described push-pull technique. Indications should exclude anatomic sites endangering neurovascular structures and local difficulties including bone overgrowth and broken or striped screws.

\section{Competing interests}

The authors declare that they have no competing interests.

\section{Authors' contributions}

MFH participated in the conception and design of the study, performed the data acquisition, participated in the statistical analysis, and drafted the manuscript. CBJ participated in the conception and design of the study, provided administrative support, carried out the critical revision of the manuscript, and supervised the study. JG participated in the data acquisition. All authors read and approved the final manuscript.

\section{Author details}

Grand Rapids Medical Education Partners, 1000 Monroe Ave NW, Grand Rapids, MI 49503, USA. ${ }^{2}$ College of Human Medicine, Michigan State University, 15 Michigan Street NE, Grand Rapids, MI 49503, USA.

${ }^{3}$ Orthopaedic Associates of Michigan, 230 Michigan Street NE, Grand Rapids, MI 49503, USA.

Received: 17 May 2012 Accepted: 5 July 2013

Published: 11 July 2013

\section{References}

1. Sanders R: When evolution begets revolution. J Orthop Trauma 2004, 18:481-482.

2. Anglen J, Kyle RF, Marsh JL, Virkus WW, Watters WC 3rd, Keith MW, Turkelson CM, Wies JL, Boyer KM: Locking plates for extremity fractures. J Am Acad Orthop Surg 2009, 17:465-472.

3. Tan SL, Balogh ZJ: Indications and limitations of locked plating. Injury 2009, 40:683-691.

4. Krettek C, Schandelmaier P, Miclau T, Tscherne H: Minimally invasive percutaneous plate osteosynthesis (MIPPO) using the DCS in proximal and distal femoral fractures. Injury 1997, 28(Suppl 1):A20-A30. 
5. Krettek C, Muller M, Miclau T: Evolution of minimally invasive plate osteosynthesis (MIPO) in the femur. Injury 2001, 32(Suppl 3):SC14-SC23.

6. Farouk $O$, Krettek C, Miclau T, Schandelmaier P, Guy P, Tscherne H: Minimally invasive plate osteosynthesis and vascularity: preliminary results of a cadaver injection study. Injury 1997, 28(Suppl 1):A7-A12.

7. Farouk $O$, Krettek C, Miclau T, Schandelmaier P, Guy P, Tscherne H: Minimally invasive plate osteosynthesis: does percutaneous plating disrupt femoral blood supply less than the traditional technique? J Orthop Trauma 1999, 13:401-406.

8. Borrelli J Jr, Prickett W, Song E, Becker D, Ricci W: Extraosseous blood supply of the tibia and the effects of different plating techniques: a human cadaveric study. J Orthop Trauma 2002, 16:691-695.

9. Pate $\mathrm{O}$, Hedequist $\mathrm{D}$, Leong $\mathrm{N}$, Hresko T: Implant removal after submuscular plating for pediatric femur fractures. J Pediatr Orthop 2009, 29:709-712.

10. Weber M, Krause F: Peroneal tendon lesions caused by antiglide plates used for fixation of lateral malleolar fractures: the effect of plate and screw position. Foot Ankle Int 2005, 26:281-285.

11. Brown OL, Dirschl DR, Obremskey WT: Incidence of hardware-related pain and its effect on functional outcomes after open reduction and internal fixation of ankle fractures. J Orthop Trauma 2001, 15:271-274.

12. Cross AW, Schmidt CC: Flexor tendon injuries following locked volar plating of distal radius fractures. J Hand Surg Am 2008, 33:164-167.

13. Henle P, Ortlieb K, Kuminack K, Mueller CA, Suedkamp NP: Problems of bridging plate fixation for the treatment of forearm shaft fractures with the locking compression plate. Arch Orthop Trauma Surg 2011, 131:85-91.

14. Vanbeek C, Boselli KJ, Cadet ER, Ahmad CS, Levine WN: Precontoured plating of clavicle fractures: decreased hardware-related complications? Clin Orthop Relat Res 2011, 469:3337-3343.

15. Clavert P, Adam P, Bevort A, Bonnomet F, Kempf JF: Pitfalls and complications with locking plate for proximal humerus fracture. J Shoulder Elbow Surg 2010, 19:489-494.

16. Loder RT, Feinberg JR: Orthopaedic implants in children: survey results regarding routine removal by the pediatric and nonpediatric specialists. J Pediatr Orthop 2006, 26:510-519.

17. Davids JR, Hydorn C, Dillingham C, Hardin JW, Pugh LI: Removal of deep extremity implants in children. J Bone Joint Surg Br 2010, 92:1006-1012.

18. Busam ML, Esther RJ, Obremskey WT: Hardware removal: indications and expectations. J Am Acad Orthop Surg 2006, 14:113-120.

19. Hallab N, Merritt K, Jacobs JJ: Metal sensitivity in patients with orthopaedic implants. J Bone Joint Surg Am 2001, 83-A:428-436.

20. Kahle WK: The case against routine metal removal. J Pediatr Orthop 1994 14:229-237.

21. Schmalzried TP, Grogan TJ, Neumeier PA, Dorey FJ: Metal removal in a pediatric population: benign procedure or necessary evil? J Pediatr Orthop 1991, 11:72-76.

22. Lovald S, Mercer D, Hanson J, Cowgill I, Erdman M, Robinson P, Diamond B: Complications and hardware removal after open reduction and internal fixation of humeral fractures. J Trauma 2011, 70:1273-1277. discussion 1277-1278.

23. Davison BL: Refracture following plate removal in supracondylarintercondylar femur fractures. Orthopedics 2003, 26:157-159.

24. Rumball K, Finnegan M: Refractures after forearm plate removal. J Orthop Trauma 1990, 4:124-129.

25. Beaupre GS, Csongradi JJ: Refracture risk after plate removal in the forearm. J Orthop Trauma 1996, 10:87-92.

26. Suzuki T, Smith WR, Stahel PF, Morgan SJ, Baron AJ, Hak DJ: Technical problems and complications in the removal of the less invasive stabilization system. J Orthop Trauma 2010, 24:369-373.

27. Langkamer $V$, Ackroyd C: Removal of forearm plates. A review of the complications. J Bone Joint Surg Br 1990, 72-B:601-604.

28. Perlick L, Tingart M, Lerch K, Bäthis H: Navigation-assisted, minimally invasive implant removal following a triple pelvic osteotomy. Arch Orthop Trauma Surg 2004, 124:64-66.

29. Salerni AA: Minimally invasive removal or revision of lumbar spinal fixation. Spine J 2004, 4:701-705.

30. Watson JT: Fractures of the forearm and elbow. Clin Sports Med 1990 9:59-83.

31. Hidaka S, Gustilo RB: Refracture of bones of the forearm after plate removal. J Bone Joint Surg Am 1984, 66:1241-1243.
32. York MJ, Hutton WC: Treatment of screw hole defects using bone graft materials: a histologic and biomechanic study. J South Orthop Assoc 1996, 5:5-12.

33. Hedequist DJ, Sink E: Technical aspects of bridge plating for pediatric femur fractures. J Orthop Trauma 2005, 19:276-279.

34. Sink EL, Hedequist D, Morgan SJ, Hresko T: Results and technique of unstable pediatric femoral fractures treated with submuscular bridge plating. J Pediatr Orthop 2006, 26:177-181.

doi:10.1186/1749-799X-8-21

Cite this article as: Hoffmann et al:: A novel technique for pediatric femoral locked submuscular plate removal: the 'push-pull' technique Journal of Orthopaedic Surgery and Research 2013 8:21.

\section{Submit your next manuscript to BioMed Central and take full advantage of:}

- Convenient online submission

- Thorough peer review

- No space constraints or color figure charges

- Immediate publication on acceptance

- Inclusion in PubMed, CAS, Scopus and Google Scholar

- Research which is freely available for redistribution 